Article

\title{
Synthesis and Characterization of New Lithium and Boron Based Metal Organic Frameworks with NLO Properties for Application in Neutron Capture Therapy
}

\author{
Domenica Marabello ${ }^{1,2, *(\mathbb{D} \text {, Paola Benzi }}{ }^{1,2}{ }^{,}$, Fabio Beccari ${ }^{1}$, Carlo Canepa ${ }^{1}$, Elena Cariati ${ }^{3}(\mathbb{D}$, \\ Alma Cioci ${ }^{1}$, Marco Costa ${ }^{4}$, Elisabetta Alessandra Durisi ${ }^{4}$, Valeria Monti ${ }^{4}$ (D), \\ Oriol Sans Planell ${ }^{4}$ and Paola Antoniotti ${ }^{1,2}$ \\ 1 Dipartimento di Chimica, University of Torino, Via P. Giuria 7, 10125 Torino, Italy; \\ paola.benzi@unito.it (P.B.); fabio.beccari@unito.it (F.B.); carlo.canepa@unito.it (C.C.); \\ alma.cioci@edu.unito.it (A.C.); paola.antoniotti@unito.it (P.A.) \\ 2 CrisDi-Interdepartmental Center for Crystallography, University of Torino, Via P. Giuria 7, \\ 10125 Torino, Italy \\ 3 Dipartimento di Chimica, University of Milano, via Golgi 19, 20133 Milano, Italy; elena.cariati@unimi.it \\ 4 Dipartimento di Fisica, University of Torino, via P. Giuria 1, 10125 Torino, Italy; marco.costa@unito.it (M.C.); \\ elisabettaalessandra.durisi@unito.it (E.A.D.); valeria.monti@unito.it (V.M.); oriol.sansplanell@unito.it (O.S.P.) \\ * Correspondence: domenica.marabello@unito.it; Tel.: +39-011-670-7505
}

Received: 13 March 2020; Accepted: 2 May 2020; Published: 9 May 2020

\begin{abstract}
In this work, we synthetized and characterized new crystalline materials with theranostic properties, i.e., they can be used both as bio-sensors and for "drug delivery". The two solid crystalline compounds studied are Metal Organic Frameworks and have formulas $\operatorname{Li}\left[\left(\mathrm{C}_{6} \mathrm{H}_{12} \mathrm{O}_{6}\right)_{2} \mathrm{~B}\right] \cdot 2 \mathrm{H}_{2} \mathrm{O}$ and $\mathrm{Li}\left[\left(\mathrm{C}_{4} \mathrm{H}_{2} \mathrm{O}_{6}\right)_{2} \mathrm{~B}\right] \cdot 5.5 \mathrm{H}_{2} \mathrm{O}$. They can be synthetized both with natural isotopes of $\mathrm{Li}$ and $\mathrm{B}$ or with ${ }^{6} \mathrm{Li}$ and ${ }^{10} \mathrm{~B}$ isotopes, that can be explored for Neutron Capture Therapy (NCT) for anti-cancer treatment. The presence of chiral organic molecules, such as mannitol and tartaric acid, provides the NLO property to the crystals and thus their capability to generate the Second Harmonic, which is useful for applications as bio-sensors. The two compounds were characterized with X-ray Diffraction and the Second Harmonic Generation (SHG) responses were estimated by theoretical calculations, and the results were compared with experimental measurements of powdered samples. In order to test the behavior of such compounds under thermal neutron irradiation, we preliminary exposed one of the two compounds in the e_LiBANS facility at the Torino Physics Department. Preliminary results are reported.
\end{abstract}

Keywords: metal organic frameworks; NLO properties; SHG efficiency; neutron capture therapy; ab-initio calculations

\section{Introduction}

Neutron Capture Therapy (NCT) is one of the radiation techniques used to treat cancer. It consists in the uptake of the stable boron-10 isotope by cancer cells and their irradiation with thermal neutrons: a nuclear reaction occurs to yield $\alpha$ particles and lithium-7 nuclei, that provide high energy along their short pathway. The efficacy of this technique is directly correlated to the amount of boron-10 deposited into each cancer cell and to the development of more selective boron delivery agents [1]. Nanoparticles are promising candidates for boron delivery agents for their improved pharmacokinetic properties, controlled and sustained release of drug, and lower systemic toxicity [2]. In this work, we aim to synthetize new solid materials containing boron nuclei with a suitable concentration, that can 
be reduced into nano-size particles and easily functionalized on the surface in order to be able to penetrate cells [3]. Boron-10 is not the only isotope that is able to capture thermal neutrons: lithium-6 nuclei can capture neutrons to yield tritium and $\alpha$ particles and deposit high energies into cells. Thus, in this work, we attempt to take advantage of the nuclear reaction of lithium-6 for NCT, concentrating both isotopes, ${ }^{10} \mathrm{~B}$ and ${ }^{6} \mathrm{Li}$, in the same nanoparticles in order to enhance the NCT efficacy.

Another requirement, for biological applications of materials, is that they should be detectable by optical microscopes, in order to determine both cell uptake and viability assay. For these purposes, we can exploit the Non-Linear Optical (NLO) properties of special non-centrosymmetric crystalline materials, that are able to emit visible light when stimulated with an infrared beam [4]. Thus, we synthetized and characterized new solid materials, containing boron and lithium atoms, and a chiral organic small molecule, which provides the NLO property to the crystal. The two organic molecules considered in this work are mannitol and tartaric acid, which have at least two vicinal $\mathrm{OH}$ groups that can link to boron. The two solid crystalline compounds obtained have the formulas $\mathrm{Li}\left[\left(\mathrm{C}_{6} \mathrm{H}_{12} \mathrm{O}_{6}\right)_{2} \mathrm{~B}\right] \cdot 2 \mathrm{H}_{2} \mathrm{O}\left(\mathrm{LiM}_{2} \mathrm{~B}\right)$ and $\mathrm{Li}\left[\left(\mathrm{C}_{4} \mathrm{H}_{2} \mathrm{O}_{6}\right)_{2} \mathrm{~B}\right] \cdot 5.5 \mathrm{H}_{2} \mathrm{O}\left(\mathrm{Li}_{5} \mathrm{~T}_{2} \mathrm{~B}\right)$. The synthesis and $\mathrm{X}$-ray crystal structures were reported. The Second Harmonic Generation (SHG) response of these two compounds was estimated by theoretical calculations and compared to experimental measurements of powdered samples. Finally, in order to test the behavior of such compounds under thermal neutron irradiation, we preliminarily exposed powdered $\mathrm{LiM}_{2} \mathrm{~B}$ to the thermal neutron radiation field of the E_LiBANS facility [5] at the Physics Department of Torino.

\section{Materials and Methods}

\subsection{Synthesis of $\mathrm{LiM}_{2} B$ and $\mathrm{Li}_{5} \mathrm{~T}_{2} B$}

All reagents, with both natural and enriched isotopes, were purchased from Sigma Aldrich. To a solution of $5.0 \mathrm{mmol}$ of mannitol or tartaric acid in $10 \mathrm{~mL}$ of water, 1.5 or $6.5 \mathrm{mmol}$ of $\mathrm{Li}_{2} \mathrm{CO}_{3}$ were slowly added, respectively. Once the evolution of $\mathrm{CO}_{2}$ stopped, $2.5 \mathrm{mmol}$ of boric acid were added and the solution was left to evaporate at room temperature. After a few weeks, the evaporation of water left a viscose residue at the bottom of the flask. Upon standing for about two months, crystals suitable for single crystal X-ray diffraction were formed and all the viscose residue crystallized. In order to speed up the synthesis, it is possible to heat the initial solution in a stove at $323 \mathrm{~K}$ without degradation of the components, and in two days, the viscose residue is formed. In any case, the formation of crystals from the viscose residue requires the same time.

\subsection{Single Crystal X-ray Diffraction (XRD)}

For both compounds, data collection was performed at room temperature on an Xcalibur, AtlasS2, Gemini Ultra diffractometer. Data integration was performed with CrysAlisPro [6]. Through Olex2 [7], the structure was solved with the ShelXT [8] structure solution program using Intrinsic Phasing and refined with the ShelXL [9] refinement package using Least Squares minimisation. All atoms but hydrogens were localized in Fourier maps and anisotropically refined. Hydrogen atoms were found in the Fourier maps and refined riding with Uiso $=1.2$ or 1.5 times Ueq of the connected atom. Details on crystal data, data collection, refinements, bond lengths and angles are reported in the Supporting Information (Tables S1-S3 for $\mathrm{LiM}_{2} \mathrm{~B}$; Tables $\mathrm{S} 4-\mathrm{S} 6 \mathrm{~s}$ for $\mathrm{Li}_{5} \mathrm{~T}_{2} \mathrm{~B}$ ) and in the deposited CIF files (CCDC 1976518 for $\mathrm{LiM}_{2} \mathrm{~B}$ and 1976411 for $\left.\mathrm{Li}_{5} \mathrm{~T}_{2} \mathrm{~B}\right)$.

\subsubsection{Crystal Data for $\mathrm{Li}\left[\left(\mathrm{C}_{6} \mathrm{H}_{12} \mathrm{O}_{6}\right)_{2} \mathrm{~B}\right] \cdot 2 \mathrm{H}_{2} \mathrm{O}\left(\mathrm{LiM}_{2} \mathrm{~B}\right)$}

$M=225.06 \mathrm{~g} / \mathrm{mol}$; orthorhombic, space group P2 ${ }_{1} 212$ (no. 18), $a=10.6384(4) \AA, b=9.7949$ (3) $\AA$, $c=9.5589(3) \AA, V=996.06(6) \AA^{3}, Z=4, \mu(\mathrm{MoK} \alpha)=0.138 \mathrm{~mm}^{-1}$, Dcalc $=1.501 \mathrm{~g} / \mathrm{cm}^{3}, 20,576$ reflections measured $(7.082 \leq 2 \Theta \leq 61.014), 3048$ unique $\left(R_{\text {int }}=0.0393, R_{\text {sigma }}=0.0220\right)$ which were used in all calculations. The final $R_{1}$ was $0.0332(\mathrm{I}>2 \sigma(\mathrm{I}))$ and $w R_{2}$ was 0.0872 (all data). 


\subsubsection{Crystal Data for $\mathrm{Li}_{5}\left[\left(\mathrm{C}_{4} \mathrm{H}_{2} \mathrm{O}_{6}\right)_{2} \mathrm{~B}\right] \cdot 5.5 \mathrm{H}_{2} \mathrm{O}\left(\mathrm{Li}_{5} \mathrm{~T}_{2} \mathrm{~B}\right)$}

$M=776.40 \mathrm{~g} / \mathrm{mol}$; orthorhombic, space group C222 1 (no. 20), $a=11.7611$ (2) $\AA, b=15.6633$ (2) $\AA$, $c=19.4260(3) \AA, V=3578.61(9) \AA^{3}, Z=4, T=293(2) \mathrm{K}, \mu(\mathrm{Cu} \mathrm{K \alpha})=1.197 \mathrm{~mm}^{-1}$, Dcalc $=1.441 \mathrm{~g} / \mathrm{cm}^{3}$, 26,418 reflections measured $(9.104 \leq 2 \Theta \leq 123.532), 2790$ unique $\left(R_{\text {int }}=0.0331, R_{\text {sigma }}=0.0159\right)$ which were used in all calculations. The final $R_{1}$ was 0.0415 (I $\left.>2 \sigma(\mathrm{I})\right)$ and $w R_{2}$ was 0.1135 (all data). The free water molecules are disordered and were treated with OLEX2 solvent mask routine (void determination) [10].

\subsection{Computational Methods}

The calculations were performed with the GAUSSIAN16 set of programs [11]. All the structures were optimized by gradient-based techniques [12-15] without symmetry constraints at the DFT B3LYP level of theory, [16,17] in conjunction with the 6-31G(d) basis set [18]. Each critical point was characterized as an energy minimum by calculating its analytical frequencies. The total dipole moment, polarizability and the first-order hyperpolarizability were calculated at the same level of theory. Despite the fact that the computational model is generally not recommended for reliable NLO calculation [19,20], the size of the fragments did not allow the use of a more suitable model. However, this level of theory has shown, in our previous works, to be in good agreement with the trend of experimental data [21-23]. Molecular volumes were computed by averaging ten different volume calculations on the optimized geometries at the B3LYP level of theory with the Gaussian16 options $\mathrm{scf}=$ tight volume $=$ tight, and $\operatorname{iop}(6 / 45=500,6 / 46=1)[24]$.

\subsection{Second Harmonic Generation Measurements}

The SHG efficiency of the powdered compounds was measured by the Kurtz and Perry method [25]. The $1064 \mathrm{~nm}$ wavelength of a Nd:YAG pulsed laser beam was directed on the sealed capillaries containing powdered samples, previously ground in an agate mortar. The scattered radiation was collected by an elliptical mirror, filtered to select only the second-order contribution, and recollected with a Hamamatsu R 5108 photomultiplier tube. The SHG efficiency was evaluated by taking the SHG signal of sucrose as reference.

\subsection{The e_LiBANS Neutron Irradiation Facility}

A new photonuclear thermal neutron facility has been developed at the Physics Department of University of Torino within the INFN e_LiBANS (Electron-LINAC Based Actively monitored Neutron Sources) project. The facility is based on a medical electron LINAC coupled to a compact converter and moderator assembly. A homogenous thermal neutron field of the order of $10^{6} \mathrm{~cm}^{-2} \mathrm{~s}^{-1}$ is achievable in the enclosed irradiation cavity with low gamma and fast neutron contaminations. Its intensity can be tuned, varying the LINAC current. These characteristics make the source appropriate for several applications such as detectors development, material studies, and BNCT preclinical research.

\section{Results and Discussion}

The compound discussed in this work can both be considered as esters of boric acid. Similar compounds with mannitol were used in the past for the titration of boric acid [26,27] and those with tartrate were studied in solution [28,29], but in both cases, no compounds were isolated in the solid state. With the synthetic method proposed in this work, it was possible to isolate the solid compounds and thus completely characterize them with X-ray Diffraction for the first time.

\subsection{Crystal Structures}

The asymmetric unit of $\mathrm{LiM}_{2} \mathrm{~B}$ consists of one half boron atom covalently bonded to two half mannitol fragments, one half $\mathrm{Li}^{+}$ion, one water molecule coordinated to the lithium atom, and one free water molecule (Figure 1). 


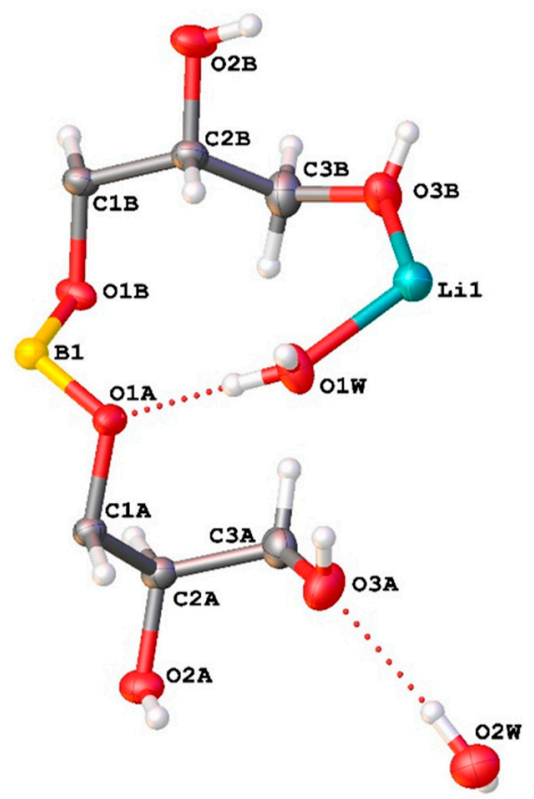

Figure 1. View of the asymmetric unit of compound $\mathrm{LiM}_{2} \mathrm{~B}$.

The boron atom is connected to the central third and fourth oxygen atoms of two mannitol fragments. The terminal hydroxyl groups of one mannitol fragment are coordinated to the $\mathrm{Li}^{+}$ions, to afford infinite one-dimensional chains (1D-MOF) parallel to the b-axis (Figure 2). Each lithium cation is coordinated by the four oxygen atoms of two $\mathrm{OH}$ groups of mannitol and of two water molecules, with an approximately tetrahedral geometry. The water molecules coordinated to the lithium ion

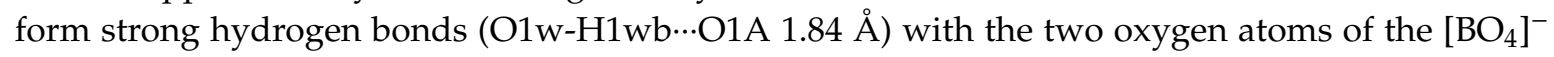
tetrahedron and contribute, together with the free water molecules, to the network of hydrogen bonds that connects the 1D-chains (Table S7).

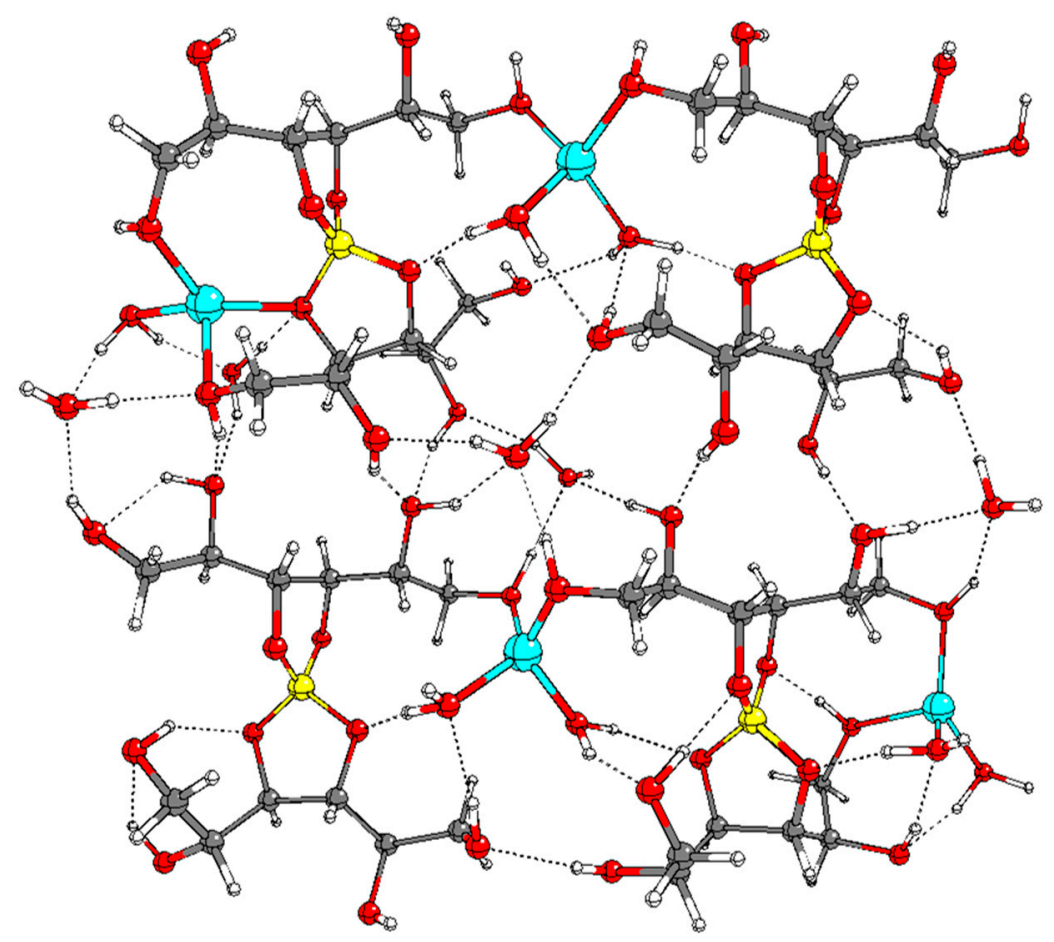

Figure 2. Fragment of the crystal structure of $\mathrm{LiM}_{2} \mathrm{~B}$ optimized at the B3LYP level of theory. 
In the asymmetric unit of compound $\mathrm{Li}_{5} \mathrm{~T}_{2} \mathrm{~B}$ there are five $\mathrm{Li}^{+}$ions, two tartrate fragments covalently bonded to one boron atom, three water molecules bonded to two lithium ions, and 5.5 free water molecules that untidily occupy the empty cavities of the crystal (Figure 3). Also in this case, the boron atom is connected to the central third and fourth carbon atoms of two tartrate fragments, forming a slightly distorted $\left[\mathrm{BO}_{4}\right]^{-}$tetrahedron. The two water molecules coordinated to the $\mathrm{Li} 5 \mathrm{ion}$ are disordered in two positions with $50 \%$ occupation factors. All the oxygens of the tartrate fragments, including the ones connected to boron, are coordinated to the lithium ions. Applying symmetries to the asymmetric unit, an intricate 3D-MOF structure is evidenced (Figure 4). It is noteworthy that the lithium ions are directly connected (bond distances from 2.933 to $3.127 \AA$ ) to form helixes along the c-axis direction (Figure 5).

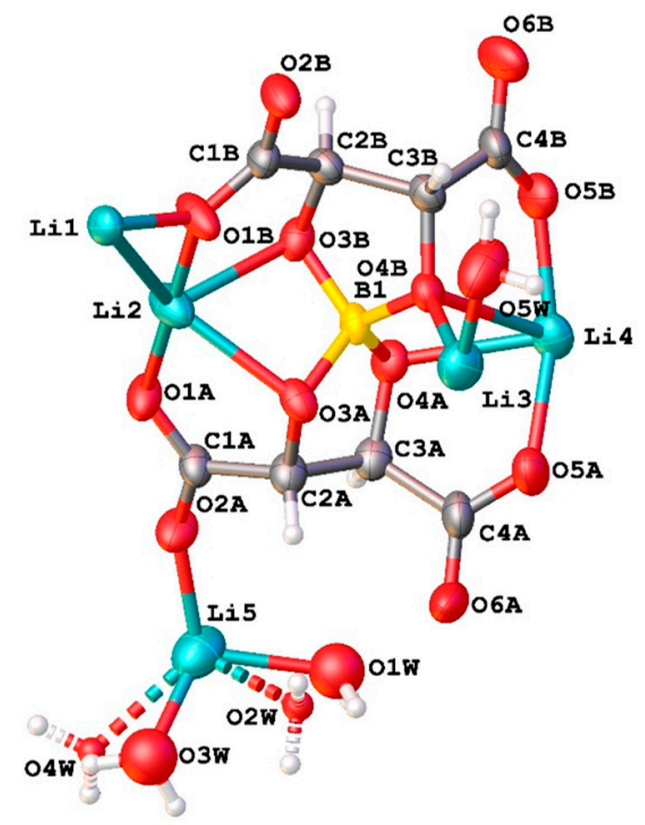

Figure 3. View of the asymmetric unit of compound $\mathrm{Li}_{5} \mathrm{~T}_{2} \mathrm{~B}$.

Despite the absence of stereogenic centers in the structures, both compounds crystallize in acentric space groups, suggesting the ability to show interesting NLO properties.

Contrary to the majority of MOF structures present in the literature, the two ones studied in this work are not porous, due to the flexibility of the organic molecules involved. This is an interesting feature for the NCT applications since they require the highest number of fissile nuclei per unit volume.

\subsection{Computational Results and SHG Measurements}

In order to penetrate in biological cells, the solid compounds $\mathrm{LiM}_{2} \mathrm{~B}$ and $\mathrm{Li}_{5} \mathrm{~T}_{2} \mathrm{~B}$ should be reduced into crystalline fragments of nanoscale size. For this reason, it is important to determine the SHG behavior of small fragments of the compounds, also considering the structural distortion that at the nanoscale level, the surface forces can induce. Therefore, small crystal fragments of the two compounds were selected (Figures 2 and 4 ) and the relevant geometries were recomputed by optimizing the atomic coordinates derived from the $\mathrm{X}$-ray structures. The fragment of $\mathrm{LiM}_{2} \mathrm{~B}$ is composed of four lithium ions, eight mannitol molecules, four boron atoms, four water molecules coordinated to the $\mathrm{Li}^{+}$ions and four free water molecules. The fragment of $\mathrm{Li}_{5} \mathrm{~T}_{2} \mathrm{~B}$ is formed by $19 \mathrm{Li}^{+}$ions, 8 tartrate molecules, 4 boron atoms, 12 water molecules bonded to 4 lithium atoms, and 6 free water molecules. Sucrose is the reference compound usually used for SHG measurements, the same type of calculation as those performed on the fragments was carried out on a model of bulk sucrose composed of four sucrose units from the crystal structure of the CSD data base. All geometries were re-optimized at the B3LYP level of theory to obtain the corresponding minima. 


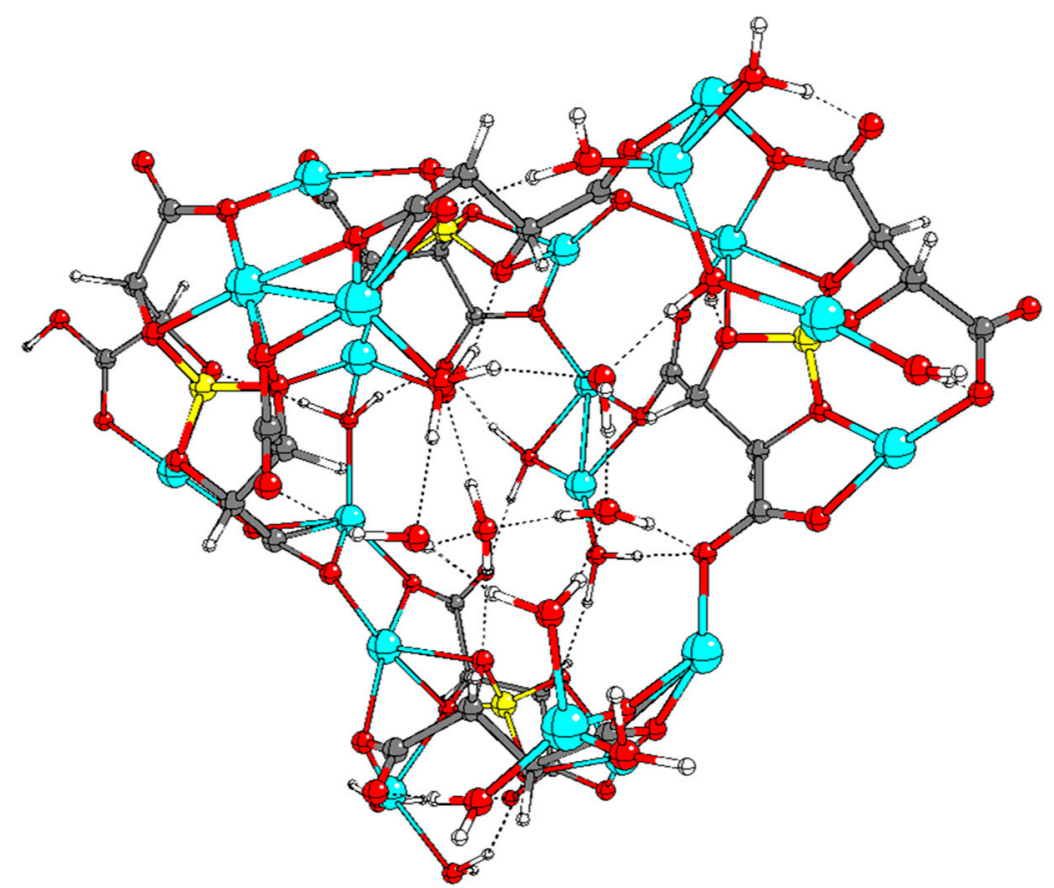

Figure 4. Fragment of the crystal structure of $\mathrm{Li}_{5} \mathrm{~T}_{2} \mathrm{~B}$ optimized at the $\mathrm{B} 3 \mathrm{LYP}$ level of theory.

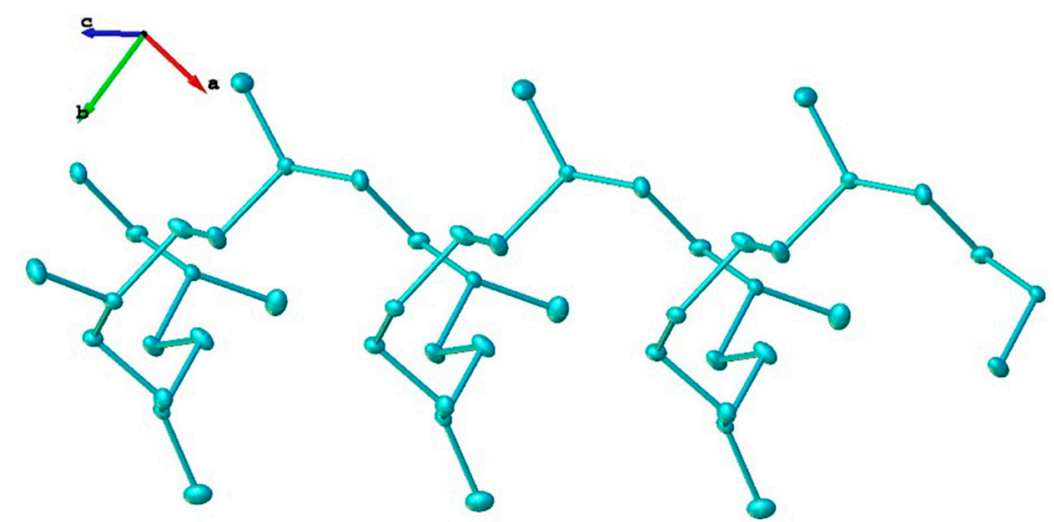

Figure 5. Infinite helix of connected lithium ions in compound $\mathrm{Li}_{5} \mathrm{~T}_{2} \mathrm{~B}$, along the $\mathrm{c}$-axis.

The average interatomic distances in $\mathrm{LiM}_{2} \mathrm{~B}$ are reported in Table 1 (complete data in Supplementary Materials, Table S2) and show small deviations from the corresponding X-ray data: the maximum difference between the calculated and experimental average atomic distances ranges between $0.4 \%$ of the $\mathrm{C}-\mathrm{O}$ averaged bond distance to $3 \%$ of the $\mathrm{Li}-\mathrm{O}$ averaged bond distance, confirming that the theoretical calculation model used is suitable to describe the $\mathrm{LiM}_{2} \mathrm{~B}$ crystal.

The optimized structural parameters of the $\mathrm{Li}_{5} \mathrm{~T}_{2} \mathrm{~B}$ complex show greater deviations from the corresponding X-ray data (Table 1 and complete data in SI, Table S5): The maximum difference between the calculated and experimental average atomic distances ranges between $0.05 \%$ of the $\mathrm{Li}-\mathrm{O}_{\mathrm{W}}$ averaged bond distance to $7 \%$ of the $\mathrm{Li} \cdots \mathrm{Li}$ averaged interatomic distance.

The total dipole moments $\mu$ and the mean polarizabilities $\langle\alpha>$ in a Cartesian frame are defined as

$$
\begin{gathered}
\mu=\left(\mu_{x}^{2}+\mu_{y}^{2}+\mu_{z}^{2}\right)^{1 / 2} \\
<\alpha>=(1 / 3)\left(\alpha_{x x}+\alpha_{y y}+\alpha_{z z}\right)
\end{gathered}
$$


The total intrinsic hyperpolarizability $\beta_{\text {tot }}$ is defined as

$$
\beta_{t o t}=\left(\beta_{x}^{2}+\beta_{y}^{2}+\beta_{z}^{2}\right)^{1 / 2}
$$

where $\beta_{x}=\beta_{x x x}+\beta_{x y y}+\beta_{x z z}, \beta_{y}=\beta_{y y y}+\beta_{y z z}+\beta_{y x x}$ and $\beta_{z}=\beta_{z z z}+\beta_{z x x}+\beta_{z y y}[30,31]$.

Table 1. Comparison between media values of selected atomic distances $(\AA)$ obtained from XRD experiment and computational optimization at B3LYP/6-31G(d) level of theory for $\mathrm{LiM}_{2} \mathrm{~B}$.

\begin{tabular}{ccccc}
\hline & \multicolumn{2}{c}{ LiM $_{\mathbf{2}}$ B } & \multicolumn{2}{c}{ Li $_{\mathbf{5}} \mathbf{T}_{\mathbf{2}} \mathbf{B}$} \\
\hline & XRD & B3LYP/6-31G(d) & XRD & B3LYP/6-31G(d) \\
\hline $\mathrm{Li}-\mathrm{O}$ & 1.944 & 2.011 & 2.096 & 2.201 \\
\hline $\mathrm{Li}-\mathrm{O}_{\mathrm{W}}$ & 1.929 & 1.987 & 1.941 & 1.942 \\
\hline $\mathrm{B}-\mathrm{O}$ & 1.471 & 1.483 & 1.474 & 1.476 \\
\hline $\mathrm{C}-\mathrm{O}$ & 1.426 & 1.431 & 1.305 & 1.317 \\
\hline $\mathrm{C}-\mathrm{C}$ & 1.526 & 1.536 & 1.535 & 1.544 \\
\hline $\mathrm{Li} \cdots \mathrm{B}$ & & & 2.682 & 2.588 \\
\hline $\mathrm{Li} \cdots \mathrm{Li}$ & & & 2.998 & 3.209 \\
\hline $\mathrm{Li} \cdots \mathrm{C}$ & & & 2.715 & 2.775 \\
\hline
\end{tabular}

The relationship between the macroscopic second-order susceptibility, the quantity that correlates to the second harmonic intensity, and the microscopic total hyperpolarizability is given by Equation (4)

$$
\chi^{(2)}=\beta_{t o t} / \varepsilon_{0} V
$$

where $V$ is the molecular volume.

In Table 2 the computed values of dipole moment $(\mu)$, mean polarizability $(<\alpha>)$, first static hyperpolarizability $\left(\beta_{t o t}\right)$, second-order susceptibility $\left(\chi^{(2)}\right)$ and measured $\mathrm{I}^{2 \omega} / \mathrm{I}^{2 \omega}$ sucrose are reported for both compounds. The ratio between the second-order susceptibility of the compounds and that of sucrose are also reported, in order to compare the computational results to the experimental SHG measurements.

Table 2. Computed dipole moments $\mu$ (Debye), mean polarizabilities $\langle\alpha\rangle$ (a.u.), first static hyperpolarizabilities $\beta_{\text {tot }}\left(10^{-30} \mathrm{~cm}^{5} \mathrm{esu}^{-1}\right)$, second order susceptibilities $\chi^{(2)}\left(\mathrm{pmV}^{-1}\right)$, and second order susceptibilities ratios with respect to sucrose values and experimental $\mathrm{I}^{2 \omega} / \mathrm{I}^{2 \omega}$ sucrose values.

\begin{tabular}{ccc}
\hline & $\mathbf{L i M}_{\mathbf{2}} \mathbf{B}$ & $\mathbf{L i}_{\mathbf{5}} \mathbf{T}_{\mathbf{2}} \mathbf{B}$ \\
\hline$\mu$ & 14.469 & 19.196 \\
$<\alpha>$ & 840.337 & 719.428 \\
$\beta$ & 3.9 & 8.0 \\
$\chi^{(2)}$ & 0.65 & 1.53 \\
$\chi^{(2)} / \chi^{(2)}$ sucrose & 0.4 & 0.8 \\
$\mathrm{I}^{2 \omega / \mathrm{I}^{2 \omega}}$ sucrose (measured) & 0.6 & 0.5 \\
\hline
\end{tabular}

Table 2 shows that the values of $<\alpha>$ are similar for the two compounds, while the dipole moments are more affected by the structural differences between the two clusters. The hyperpolarizability $\beta$ values are also influenced by the cluster structure, $\mathrm{Li}_{5} \mathrm{~T}_{2} \mathrm{~B}$ showing a value twice that of $\mathrm{LiM}_{2} \mathrm{~B}$. The static susceptibility $\chi^{(2)}$ is a macroscopic property that depends on the molar volume: since the molar volume of $\mathrm{Li}_{5} \mathrm{~T}_{2} \mathrm{~B}$ is lower, the $\chi^{(2)}$ is more than two times that of $\mathrm{LiM}_{2} \mathrm{~B}$.

Comparing the trend of $\chi^{(2)} / \chi^{(2)}$ sucrose ratio with respect to the measured $\mathrm{I}^{2 \omega} / \mathrm{I}^{2 \omega}$ sucrose, we can conclude that both the computational and experimental methods give similar SHG efficiency for both 
compounds, and it is slightly lower than sucrose. This result is not considered optimal for biosensor applications, but suggests that the SHG intensity emitted by both compounds can be detected by a suitable microscope.

\subsection{The Neutron Irradiation Campaign}

To preliminarily test the behavior of the powdered $\mathrm{LiM}_{2} \mathrm{~B}$ under thermal neutron irradiation, we analyzed the X-ray Diffraction Powder patterns (XRPD) collected with a single crystal diffractometer, both before and after irradiation. For both $\mathrm{LiM}_{2} \mathrm{~B}$ and ${ }^{6} \mathrm{LiM}_{2}{ }^{10} \mathrm{~B}$, a ball of powder of $0.45 \mathrm{~mm}$ diameter (less than the collimator diameter of the X-ray beam $0.5 \mathrm{~mm}$ ) was prepared, compacting the powder with paraffin oil. The balls were placed on a glass capillary inserted in a small wood tube mounted in the goniometer head for the pattern collection or in a polystyrene disc for the neutron irradiation. The XRPD patterns were collected before and after irradiation with thermal neutron fluences of $1.2 \times 10^{10} \mathrm{~cm}^{-2}, 3.6 \times 10^{10} \mathrm{~cm}^{-2}$ and $1.0 \times 10^{11} \mathrm{~cm}^{-2}$.

The fraction of nuclei absorbing thermal neutrons with a fluence of $1.0 \times 10^{11} \mathrm{~cm}^{-2}$ are $3.42 \times 10^{-10}$ for ${ }^{10} \mathrm{~B}$ and $8.36 \times 10^{-11}$ for ${ }^{6} \mathrm{Li}$. Thus, a very limited fraction of the enriched nuclei is involved in the nuclear reactions. However, if we consider that each emitted alpha can damage a significant number of crystal sites around the point of emission, we could expect the damaged fraction of the crystalline material to be detectable in the powder patterns.

A detail of the patterns in the $2 \theta$ range between 10 and $20 \mathrm{deg}$ is reported in Figure 6 . Effective neutron activation of ${ }^{6} \mathrm{Li}$ and ${ }^{10} \mathrm{~B}$ isotopes should result in an appreciable decrease of the diffraction peak intensities, due to the local destruction of the crystal lattice.

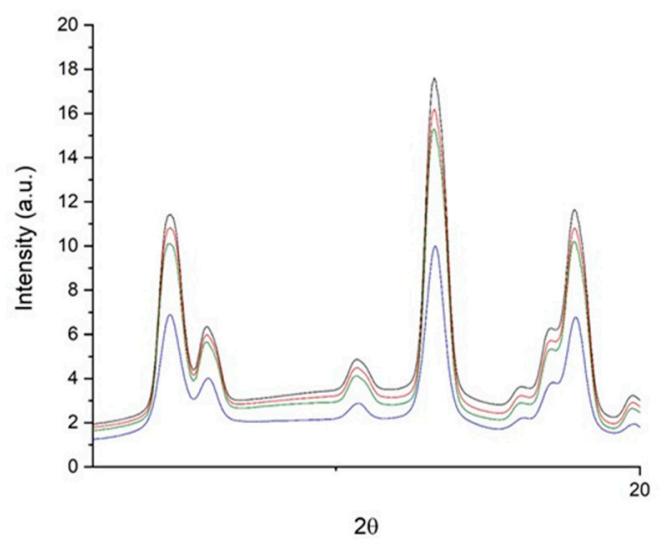

(a)

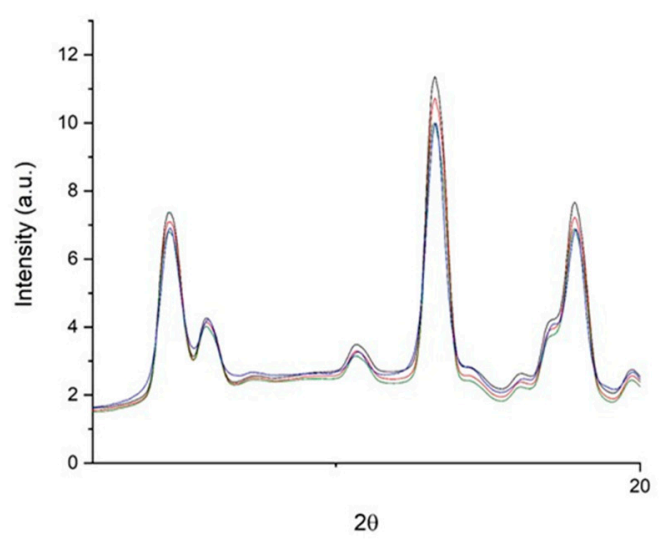

(b)

Figure 6. Powder patterns collected for ${ }^{6} \mathrm{LiM}_{2}{ }^{10} \mathrm{~B}(\mathbf{a})$ and $\mathrm{LiM}_{2} \mathrm{~B}(\mathbf{b})$ before neutron radiation (black line), after irradiation with thermal neutron fluences of $1.210^{10} \mathrm{~cm}^{-2}$ (red line), $3.610^{10} \mathrm{~cm}^{-2}$ (green line) and $1.010^{11} \mathrm{~cm}^{-2}$ (blue line).

The patterns of both the enriched and natural samples exhibit a comparable decrease of intensity of the irradiated with respect to the non-irradiated sample up to the fluence $3.6 \times 10^{10} \mathrm{~cm}^{-2}$. However, after irradiation with the maximum fluence of $1.0 \times 10^{11} \mathrm{~cm}^{-2}$, a significant lowering the intensity of all peaks is detectable in the enriched sample, but not so in the natural sample. These are encouraging results, although still affected by a high statistical error. Further irradiation experiments can help achieve more quantitative results.

\section{Conclusions}

In this work, we introduced a new type of solid materials that could be used for applications in SHG biosensors and, once enriched with ${ }^{6} \mathrm{Li}$ and ${ }^{10} \mathrm{~B}$, for application in NCT. 
Unfortunately, both theoretical and experimental analysis demonstrated that the two compounds studied exhibit low intensity of the SHG with respect to sucrose. However, for biological purposes, their SHG intensity should be sufficient to be detected with a suitable SHG microscope. In any case, it should be preferable to produce new similar compounds more efficient in the SHG and this will be the purpose of future syntheses.

From the point of view of NCT applications, the preliminary tests on the effects of neutron irradiation on the two compounds are encouraging, although not quantitatively conclusive. The improvement of this method will be the subject of future works.

In general, we expect the effect of neutron irradiation on biological cells with inserted enriched nanoparticles of such compounds to be more pronounced, since cells are more sensitive to the damage of alpha particles emitted by ${ }^{10} \mathrm{~B}$ and ${ }^{6} \mathrm{Li}$ with respect to the crystal. Therefore, since biological experiments on cells are time consuming, a method that can preliminarily test the effects of neutron irradiation on crystals could be very useful to screen candidate compounds and select those that are best suited for subsequent in vitro experiments.

Supplementary Materials: The following are available online at http://www.mdpi.com/2227-9717/8/5/558/s1, Table S1: Crystal data and structure refinement for $\mathrm{LiM}_{2} \mathrm{~B}$, Table S2. Bond lengths for $\mathrm{LiM}_{2} \mathrm{~B}$ from X-ray diffraction and theoretical calculations, Table S3: Bond angles for $\mathrm{LiM}_{2} \mathrm{~B}$ from XRD, Table S4: Crystal data and structure refinement for $\mathrm{Li}_{5} \mathrm{~T}_{2} \mathrm{~B}$, Table S5: Bond lengths for $\mathrm{Li}_{5} \mathrm{~T}_{2} \mathrm{~B}$ from X-ray diffraction and theoretical calculations, Table S6: Bond angles for $\mathrm{Li}_{5} \mathrm{~T}_{2} \mathrm{~B}$ from X-ray diffraction, Table S7. Strong hydrogen bond lengths and angles for $\mathrm{LiM}_{2} \mathrm{~B}$ and $\mathrm{Li}_{5} \mathrm{~T}_{2} \mathrm{~B}$ from $\mathrm{X}$-ray diffraction and theoretical calculations, Figure S1: Infinite linear thread showed in the structure of compound $\mathrm{LiM}_{2} \mathrm{~B}$ Figure S2: View of the $\mathrm{Li}_{5} \mathrm{~T}_{2} \mathrm{~B}$ structure.

Author Contributions: Conceptualization, D.M. and C.C.; methodology, D.M., C.C., P.B., M.C., E.A.D.; formal analysis, F.B., E.C., V.M. and O.S.P.; investigation, P.A. and A.C.; writing-review and editing, project administration and funding acquisition, D.M. All authors have read and agreed to the published version of the manuscript.

Funding: This research was funded by MIUR (Ministero dell'Istruzione, dell'Università e della Ricerca) and Fondazione CRT.

Conflicts of Interest: The authors declare no conflict of interest.

\section{References}

1. Nedunchezhian, K.; Aswath, N.; Thiruppathy, M.; Thirugnanamurthy, S. Boron Neutron Capture Therapy-A Literature Review. J. Clin. Diagn. Res. 2016, 10, 2E01-2E04. [CrossRef] [PubMed]

2. Moss, R.L. Critical review, with an optimistic outlook, on Boron Neutron Capture Therapy (BNCT). Appl. Rad. Isot. 2014, 88, 2-11. [CrossRef] [PubMed]

3. Marabello, D.; Antoniotti, P.; Benzi, P.; Beccari, P.; Canepa, C.; Barge, A.; Boscaro, V.; Gallicchio, M.; Peira, E. Synthesis, characterization and cell uptake of nanoparticles for a novel approach to radionuclide therapy: A feasibility study. Int. J. Res. Pharm. Nano Sci. 2019, 8, 230-240. Available online: http: $/ /$ www.ijrpns.com/archives1.php?volume $=8 \&$ issue $=5$ (accessed on 5 July 2019).

4. Boyd, R.W. Nonlinear Optics; Academic Press-An imprint of Elsevier Science: San Diego, CA, USA, 2003; ISBN 0-12-121682-9.

5. Monti, V.; Costa, M.; Durisi, E.; Mafucci, E.; Menzio, L.; Sans-Planell, O.; Visca, L.; Bedogni, R.; Treccani, M.; Pola, A.; et al. The e LiBANS facility: A new compact thermal neutron source based on a medical electron, LINAC. Nuclear Instrum. Methods Phys. Sect. A 2020, 953, 163154. [CrossRef]

6. CrysAlisPro 1.171.39.46 (Rigaku Oxford Diffraction, 2018). Available online: https://www.rigaku.com/ products/smc/crysalis (accessed on 5 July 2019).

7. Dolomanov, O.V.; Bourhis, L.J.; Gildea, R.J.; Howard, J.A.K.; Puschmann, H. OLEX2: A complete structure solution, refinement and analysis program. J. Appl. Crystallogr. 2009, 42, 339-341. [CrossRef]

8. Sheldrick, G.M. SHELXT-Integrated space-group and crystal-structure determination. Acta Crystallogr. 2015, A71, 3-8. [CrossRef]

9. Sheldrick, G.M. Crystal structure refinement with SHELXL. Acta Crystallogr. 2015, C71, 3-8.

10. Jiang, J.S.; Brünger, A.T. Protein hydration observed by X-ray diffraction. J. Mol. Biol. 1994, 243, 100-115. [CrossRef] 
11. Frisch, M.J.; Trucks, G.W.; Schlegel, H.B.; Scuseria, G.E.; Robb, M.A.; Cheeseman, J.R.; Scalmani, G.; Barone, V.; Petersson, G.A.; Nakatsuji, H.; et al. Gaussian 16, Revision C.01; Gaussian, Inc.: Wallingford, CT, USA, 2016.

12. Schlegel, H.B.; Daudel, C. Computational Theoretical Organic Chemistry; Reidel Publ, Co.: Dordrecht, The Netherlands, 1981.

13. Schlegel, H.B. An efficient algorithm for calculating ab initio energy gradients using s, p Cartesian Gaussians. J. Chem. Phys. 1982, 77, 3676-3681. [CrossRef]

14. Schlegel, H.B. Optimization of equilibrium geometries and transition structures. J. Comput. Chem. 1982, 3, 214-218. [CrossRef]

15. Schlegel, H.B.; Binkley, J.S.; Pople, J.A. First and second derivatives of two electron integrals over Cartesian Gaussians using Rys polynomials. J. Chem. Phys. 1984, 80, 1976-1981. [CrossRef]

16. Becke, A.D. Density-functional exchange-energy approximation with correct asymptotic behavior. Phys. Rev. A 1988, 38, 3098-3100. [CrossRef] [PubMed]

17. Becke, A.D. Densityfunctional thermochemistry. III. The role of exact exchange. J. Chem. Phys. 1993, 98, 5648-5652. [CrossRef]

18. Hehre, W.J.; Radom, L.; Schleyer, P.R.; Pople, J.A. Ab Initio Molecular Orbital Theory; Wiley: New York, NY, USA, 1986.

19. Hrobáriková, V.; Hrobárik, P.; Gajdos, P.; Fitilis, I.; Fakis, M.; Persephonis, P.; Zahradník, P. Benzothiazole-Based Fluorophores of Donor- $\pi$-Acceptor- $\pi$-Donor Type Displaying High Two-Photon Absorption. J. Org. Chem. 2010, 75, 3053-3068. [CrossRef] [PubMed]

20. Hrobárik, P.; Sigmundová, I.; Zahradník, P.; Kasák, P.; Arion, V.; Franz, E.; Clays, K. Molecular Engineering of Benzothiazolium Salts with Large Quadratic Hyperpolarizabilities: Can Auxiliary Electron-Withdrawing Groups Enhance Nonlinear Optical Responses? J. Phys. Chem. C 2010, 114, 22289-22302. [CrossRef]

21. Marabello, D.; Antoniotti, P.; Benzi, P.; Canepa, C.; Diana, D.; Operti, L.; Mortati, L.; Sassi, M.P. Non Linear Optical Properties of $\beta$-D-Fructopyranose Calcium Chloride MOFs: An Experimental and Theoretical Approach. J. Mater. Sci. 2015, 50, 4330-4341. [CrossRef]

22. Marabello, D.; Antoniotti, P.; Benzi, P.; Canepa, C.; Mortati, L.; Sassi, M.P. Synthesis, structure and non-linear optical properties of new isostructural $\beta$-D-fructopyranose alkaline halide metal-organic frameworks: A theoretical and an experimental study. Acta Crystallogr. 2017, B73, 737-743. [CrossRef]

23. Marabello, D.; Antoniotti, P.; Benzi, P.; Cariati, E.; Lo Presti, L.; Canepa, C. Developing new $\mathrm{SrI}_{2}$ and $\beta$-D-fructopyranose-based metal-organic frameworks with nonlinear optical properties. Acta Crystallogr. 2019, B75, 210-218. [CrossRef]

24. Parsons, D.F.; Ninham, B.W. Ab initio molar volumes and Gaussian radii. J. Phys. Chem. A 2009, 113, 1141-1150. [CrossRef]

25. Kurtz, S.K.; Perry, T.T. A powder technique for the evaluation of nonlinear optical materials. J. Appl. Phys. 1968, 39, 3798-3813. [CrossRef]

26. Davis, H.B.; Mott, C.J.B. Interaction of Boric Acid and Borates with Carbohydrates and Related Substances. J. Chem. Soc. Faraday 1 1980, 76, 1991-2002. [CrossRef]

27. Celeste, M.; Avezedo, C.; Cavailero, A.M.V. The Acid-Base Titration of a Very Weak Acid: Boric Acid. J. Chem. Educ. 2012, 89, 767-770.

28. Pizer, R.; Ricatto, P.J. Ternary alkaline earth metal complex ions in the M2+/borate/tartrate system as studied by 11B NMR. Inorg. Chem. 1994, 33, 4985-4990. [CrossRef]

29. Kustin, K.; Pizer, R. Temperature-Jump Study of the Rate and Mechanism of the Boric Acid-Tartaric Acid Complexation. J. Am. Chem. Soc. 1969, 91, 317-322. [CrossRef]

30. Kanis, D.R.; Ratner, M.A.; Marks, T.J. Design and construction of molecular assemblies with large second-order optical nonlinearities.Quantum chemical aspects. Chem. Rev. 1994, 94, 195-242. [CrossRef]

31. Kyrill, Y.; Suponitsky, K.Y.; Tafur, S.; Masunov, A.E. Applicability of hybrid density functional theory methods to calculation of molecular hyperpolarizability. J. Chem. Phys. 2008, 129, 044109.

(C) 2020 by the authors. Licensee MDPI, Basel, Switzerland. This article is an open access article distributed under the terms and conditions of the Creative Commons Attribution (CC BY) license (http://creativecommons.org/licenses/by/4.0/). 